\title{
Aging and geriatric palliative care
}

\author{
๑D Orkun Sarıçam ${ }^{1}$, @Kadriye Kahveci \\ ${ }^{1}$ Pursaklar State Hospital, Department of Internal Medicine Clinic, Ankara, Turkey \\ ${ }^{2}$ Ankara City Hospital, Department of Anesthesology and Reanimation, Ankara, Turkey
}

Cite this article as: Sarıçam O, Kahveci K. Aging and geriatric palliative care. Anatolian Curr Med J 2021; 3(3); 251-255.

\begin{abstract}
The rise in the prevalence of chronic diseases and the growing number of persons, who cannot continue living alone, emerge as a serious problem in parallel to the increased life expectancy around the globe. Geriatrics and palliative care overlap in many ways, although they are different medical specialties. Both are multidisciplinary fields aiming to improve the patient's quality of life, personal abilities, and participation in social activities through patient and family-centered activities. We think that the synergy generated by the collaboration between these two specialties will become a model for interdisciplinary collaboration in healthcare and improve the quality of life of patients.
\end{abstract}

Keywords: Geriatrics, palliative care, systemic changes

\section{INTRODUCTION}

The World Health Organization (WHO) defines individuals aged 65 and over as old persons. Old age is the accumulation of a series of cellular and molecular damages that leads to a decline in physiological capacity and an increase in the risk of developing various diseases (1). Gerontology is a medical specialty which deals with the health problems, social and functional lives, and the quality of life of patients over 65 years of age. Furthermore, preventive medicine practices in the geriatric population and the aging society are other fields of gerontology. The average life expectancy of people has increased throughout the world and the geriatric population is growing day after day (2). Such changes are invoking serious problems along with the increases in the prevalence of chronic diseases and the rise in the number of people, who cannot continue to live alone. The increased life expectancy is associated with aging-associated significant problems that affect the quality of life.

Geriatrics and palliative care (PC) overlap in many ways, although they are different medical specialties (3). Both are multidisciplinary fields aiming to improve the patient's quality of life, personal abilities, and social participation through both patient-centered and familycentered activities (4). To achieve improvements in the quality of life is the common purpose in geriatrics and PC. The aims of both specialties are remarkable because they evaluate the individual not only from the medical aspect but evaluate the individual's social environment as well while taking the individual's values, preferences, and needs into account (5). Olden et al. showed that the majority of the patients referred to palliative care were 65 years old and that, especially, those aged 85 and over were consulted more frequently for end-of-life care (6). The increased prevalence of dementia in old persons adds to the complexity and complications of patient management issues, especially in individuals over 80 years of age (7).

In geriatric palliative care, the aim is to improve the quality of life and alleviate pain through the treatment and prevention of symptoms rather than diseases during the process of the provision of care to old persons suffering from serious and life-threatening diseases (3). The incidences of life-threatening diseases such as cardiac, cerebrovascular, and respiratory diseases, and cancer increase in the geriatric age group (8). Of individuals at 65 years of age or over, approximately two-thirds have two or more chronic diseases and one-third have more than three diseases. Disease factors, symptoms, and signs, too, occur differently in geriatric patients. Furthermore, the coexistence of multiple pathologies and the administration of polypharmacy are common in this age group (9). As the number of older adults living with multiple chronic illnesses continues to increase, so too does the need to develop targeted screening, referral processes and geriatrics palliative cares for managing these patients' often complicated symptom presentations (10) 
Table 1. Systemic changes in old individuals

1. Cardiovascular system

2. Respiratory system

3. Genitourinary system

4. Nervous system

5. Gastrointestinal system

6. Metabolic and endocrine system

7. Musculoskeletal system

8. Skin changes and sensory functions

9. Immune system

\section{SYSTEMIC CHANGES IN OLD INDIVIDUALS}

\section{Cardiovascular System}

The World Health Organization states that $39 \%$ of 40 million people with cardiovascular diseases need PC each year but, of those individuals, $86 \%$ cannot have access to such care (11). Cardiovascular diseases in the geriatric population are the most significant causes of morbidity and mortality. The loss and degeneration of muscle cells, increases in connective tissue proportions, reduced vascular elasticity, and increased fibrosis and calcification in cardiac valves are common changes observed during the aging process $(12,13)$. Therefore; the incidence and prevalence of cardiac diseases such as coronary heart disease, atherosclerosis, arrhythmias, and valvular heart diseases are found high in the geriatric population (14).

Geriatric cardiology practices have recently come to the forefront aiming to combine the goals of improving and advancing the provision of care to old persons and to adapt such practices to the needs of individual patients in large healthcare institutions (15). Geriatric cardiology combines cardiovascular perspectives with multimorbidity, polypharmacy, frailty, cognitive decline, and other clinical, social, financial, and psychological dimensions of aging. At the same time, it aims to facilitate the coordination across clinicians from various specialties, including specialists and subspecialists from medical and surgical fields along with physiotherapists and palliative care specialists in order to improve the provision of care to old persons (16).

\section{Respiratory System}

Functional and anatomical deformations occur over time and the lung capacity decreases with advancing age. The structures of collagen and elastin in the lung undergo alterations leading to significant progressive decreases in the forced vital capacity, diffusing capacity, gas exchange, ventilation, and respiratory sensitivity (17). The prevalence of chronic obstructive pulmonary disease (COPD) in older individuals increases two-tothree folds. Pneumonia is an important cause of death in older individuals and susceptibility to respiratory system infections increases in this population because of immune system alterations (18).
Patients with chronic lung disease have a high symptom burden and their symptom burden is even higher compared to patients with cancer and other chronic diseases (19). Palliative care aims for symptom alleviation in old individuals with chronic lung disease through the management of dyspnea and the combination of pharmacological and nonpharmacological interventions (20).

\section{Genitourinary System}

Along with aging; functional kidney tissue is lost, the blood supply to the kidneys decreases, the glomerular filtration rate slows down, the secretion and absorption capacities of the kidneys decrease, and progressive loss of nephrons occurs. Kidneys' capacity to concentrate urine and retain sodium decreases leading to electrolyte imbalance due to impairments in the perception of thirst. Bladder capacity decreases and the incidence of urinary tract infections increases resulting from the weakening of the bladder muscles causing an increased residual volume of urine (21).

Pharmacokinetic changes occur in the absorption, distribution, metabolism, and excretion of anesthetic drugs in geriatric patients. The incidence of chronic kidney disease (CKD) rises (22). Complaints such as the enlargement of the prostate gland, difficulties in bladder emptying, and frequent urination in small volumes develop in men along with advancing age. Vaginal atrophy, decreased uterine volume, and atrophy of mammary glands occur due to low levels of estrogen and progesterone in women in advanced ages. Besides, the incidence of stress incontinence is found to increase. The quality of life is impaired in urinary incontinence and with the limitation of physical activity. Furthermore; the incidences of hypertension, osteoporosis, coronary heart disease, and psycho-social problems increase in this age group (23).

Despite ongoing efforts to improve the quality of care; patients with progressed CKD continue to experience significant physical, emotional, and mental suffering. In the last months of their lives, many elderly patients undergoing dialysis face many disease complications. Palliative care for these patients focuses on optimizing disease management and addressing the needs of patients and caregivers broadly (24).

\section{Nervous System}

The blood supply to the brain decreases, meninges thicken, and ventricles expand with aging. Continuing neuron loss accompanied by the degeneration of the vessels providing blood supply to the brain causes the occurrence of symptoms in association with aging (25). Natural cognitive changes associated with aging are observed; including mild impairments, particularly in 
memory planning and processing speed, and learning capacity. However, such functional impairments are not significant enough to interfere with daily life. Breakdown of knowledge, loss of vocabulary, and communication and perception disorders are not anticipated in old individuals without dementia (26). Leading neurological diseases with increasing incidences in parallel to the aging process are neurodegenerative disorders including Alzheimer's disease, Parkinson's disease (PD), multiple system atrophy (MSA), progressive supranuclear palsy (PSP), Lewy body dementia (LCD), frontotemporal dementia (FTD), amyotrophic lateral sclerosis (ALS), and stroke (27).

The density of brain vessels changes in each decade of life. A decrease in areas with dense capillaries and an increase in the degree and number of micro-vessel deformities start to occur with advancing age (28). Advanced age is one of the unmodifiable risk factors for both hemorrhagic and ischemic stroke. The risk of stroke doubles every 10 years in men and women after 55 years of age (29). Palliative care professionals (in inpatient, outpatient, or residential service settings) interacting with patients and families affected by neurological diseases need to comprehend basic principles of care specific to neurological disorders, including prognosis, prognostic uncertainty, and unique aspects of impacts of the disease (30).

\section{Gastrointestinal System}

In advanced ages, peristaltic movements slow down and swallowing reflexes become impaired due to the loss of elastic tissue around the oropharynx. The decreased population of gustatory cells in the tongue and the oral cavity and changes in salivary functions are observed. Tooth loss occurs due to physiological erosions in the tooth enamel and the reduced density of blood vessels, nerves, and lymphatic vessels entering the pulp (31). Esophageal muscles start losing tonus. The stomach loses its elasticity resulting in slowing down gastric emptying. Secretion of gastric acid and the intrinsic factor is reduced in the stomach (32). Consequent to such changes in the gastrointestinal system; gastrointestinal bleeding, progressive constipation leading to ileus, atrophic gastritis, peptic ulcer, duodenal ulcer, loss of appetite, and malnutrition are frequently seen in the geriatric age group. In the aging process, the hepatic blood flow decreases along with the volume loss in the liver. The total capacity of the liver to metabolize drugs decreases, too (21).

\section{Metabolic and Endocrine System}

Aging causes reductions in endocrine functions, tissue sensitivity, and hormone secretion from peripheral glands. The circadian hormonal rhythm slows down along with increasing age (33). Diabetes prevalence in older adults is more than twice that of middle-aged adults (34). Risk of cardiovascular events, loss of skeletal mass, vasomotor instability, psychological symptoms, and atrophy of estrogen-sensitive tissue increase in parallel to reductions in estrogen levels in women. Male gonadal steroid production changes with aging and that condition is called andropause. Furthermore, total serum testosterone concentrations start to decrease in men along with aging (33).

\section{Musculoskeletal System}

Bone density decreases and poor body posture develops with aging. Bone density starts to decrease and bone remodeling increases around 40-50 years of age on average, causing reductions in body height in both sexes (35). About half of the muscle mass is lost in individuals around 75 years of age. The isometric muscle contraction strength decreases besides the reduction in the muscle mass (36).

\section{Skin Changes and Sensory Functions}

Fibrous proteins such as collagen and elastin decrease in quantity in old individuals. Quantities of glycosaminoglycan and proteoglycan and similar substances decrease, too. Thinning of the epidermis is observed due to the deceleration of cell renewal. Loss of connective tissue elasticity is observed in old persons. For this reason, the skin of old individuals is thin and fragile. In old age, the sensitivity of touch receptors is reduced and heat, cold, and pressure sensations in hands and feet become poor (37). The protection capacity of the skin against ultraviolet (UV) light is reduced as the number of melanocytes decreases (38).

Sensorial perception decreases with aging. The ability to focus on close objects decreases and the visual acuity and peripheral vision become less sharp. Tear secretion decreases, the conjunctiva becomes thinner and acquires a yellowish tint, and cataracts develop. Old persons start to have difficulty in hearing high-frequency sounds. Taste and smell sensations may become less sharp, too. Furthermore, stimuli may be perceived differently (39).

\section{Immune System}

The balance between protective and pathogenic immune responses is impaired with aging. Reduction in T-cell functions leads to a reduction in cellular and humoral immunity. Changes in B-cell functions appear to be less important. Susceptibility to infections develops and responses to vaccination and defenses against cancer lose strength. Advanced age increases the risk of autoimmunity. Autoantibody formation increases in old individuals (40). 


\section{CONCLUSION}

The last stages of life are characterized by changes in individuals of aging societies in a way that traditional care services in geriatrics and PC cannot meet the emerging needs. To meet such unmet needs, both specialties should act in close collaboration and geriatric palliative care should be conceptualized as an interdisciplinary care and research field based on care ethics. Increased life expectancy and changes associated with end-oflife morbidity predict major challenges for healthcare. For most old individuals, the last two decades of life are characterized by the increased burden of functional and chronic multimorbidity with a potential to cause an emerging need for geriatric care because of the occurrence of dependency, frailty, and often cognitive decline $(41,42)$. At the same time, the end-of-life period may represent a long and challenging process complicated by difficulties in symptom management, complex treatment decisions, easily overlooked psychological distress, and a wide range of psychosocial problems.

Geriatrics is a medical specialty focusing on the provision of healthcare to old persons. The specialty of geriatrics has been evolved to increase functional abilities and solve physical, mental, social, and moral problems of old individuals; thus aiming to increase the quality of life and social participation in order to counteract the unfavorable effects of multimorbidity in the growing population of geriatric patients. Geriatrics and PC are overlapping medical specialties. Both are professional and interdisciplinary fields administering patient and familycentered activities to improve the quality of life, personal abilities, and social inclusion. We strongly believe that the synergy that will be generated through the collaboration of these two interrelated specialties will serve as a model for cross-specialty collaboration in healthcare.

\section{ETHICAL DECLARATION}

Referee Evaluation Process: Externally peer-reviewed.

Conflict of Interest Statement: The authors have no conflicts of interest to declare.

Financial Disclosure: The authors declare that no funds were received.

Author Contributions: All of the authors declare that they all participated in the design and the conduct of the study. All authors have approved the final version.

\section{REFERENCES}

1. Global Health and Aging, National Institute of Aging, NIH, WHO, 2011

2. Department of Economic and Social Affairs, Population Division, United Nations. World Population Ageing 2015. New York: United Nations; 2015. 164 p.
3. Voumard R, Truchard ER, Benaroyo L, Borasio GD, Büla C, Jox RJ. Geriatric palliative care: a view of its concept, challenges and strategies. BMC Geriatr 2018; 18: 220.

4. Albers G, Froggatt K, Block LV, et al. A qualitative exploration of the collaborative working between palliative care and geriatric medicine: barriers and facilitators from a European perspective. BMC Palliat Care 2016; 15: 47.

5. Şahin S. Geriatride Palyatif Bakım. Türkiye Klinikleri J Anesthesiol Reanimat Spec Topics 2017; 10: 36-41.

6. Olden AM, Holloway R, Ladwig S, Quill TE, van Wijngaarden E. Palliative care needs and symptom patterns of hospitalized elders referred for consultation. J Pain Symptom Manag 2011; 42: 410-8.

7. Evers MM, Meier DE, Morrison RS. Assessing differences in care needs and service utilization in geriatric palliative care patients. J Pain Symptom Manage 2002; 23: 424-32.

8. Sanford AM, Morley JE, Weger MB, et al. High prevalence of geriatric syndromes in older adults. PLoS One 2020; 15: e0233857.

9. Marengoni A, Angleman S, Meinow B, et al. Coexisting chronic conditions in the older population: variation by health indicators. Eur J Intern Med 2016; 31: 29-34.

10. Kapo J, Morrison LJ, Liao S. Palliative care for the older adult. J Palliat Med 2007; 10: 185-209.

11. Connor SR, Bermedo MCS. Worldwide Palliative Care Alliance. World Health Organization. Global Atlas of Palliative Care at the End of Life. London: Worldwide Palliative Care Alliance; 2014.

12. Fox CS, Vasan RS, Parise H, et al. Mitral annular calcification predicts cardiovascular morbidity and mortality: The Framingham Heart Study. Circulation 2003; 107: 1492-6.

13. Redfield MM, Jacobsen SJ, Borlaug BA, Rodeheffer RJ, Kass DA. Age- and gender-related ventricular-vascular stiffening: A community-based study. Circulation 2005; 112 :2254-62.

14. Alagiakrishnan K, Banach M, Mah D, Ahmed A, Aronow WS. Role of geriatric syndromes in the management of atrial fibrillation in older adults: a narrative review. J Am Med Dir Assoc 2019; $20: 123-30$

15. Wu Q, Li LF, Chen YD. Advances in Journal of Geriatric Cardiology over the course of a decade. J Geriatr Cardiol 2020; 17: 733-9.

16. Bell SP, Orr NM, Dodson JA, et al. What to expect from the evolving field of geriatric cardiology. J Am Coll Cardiol 2015; 66: 1286-99.

17. Thannickal VJ, Murthy M, Balch WE, et al. Blue Journal Conference. Aging and susceptibility to lung disease. Am J Respir Crit Care Med 2015; 191: 261-9.

18. Boe DM, Boule LA, Kovacs EJ. Innate immune responses in the ageing lung. Clin Exp Immunol 2017; 187: 16-25.

19. Walke LM, Byers AL, Tinetti ME, Dubin JA, McCorkle R, Fried TR. Range and severity of symptoms over time among older adults with chronic obstructive pulmonary disease and heart failure. Arch Intern Med 2007; 167: 2503-08

20. Mularski RA, Rocker G. Managing dyspnea in advanced chronic obstructive pulmonary disease: Balancing all the evidence. Ann Am Thorac Soc 2015; 12: 978-80

21. Alvis BD, Christopher G. Hughes, physiology considerations in the geriatric patient. Anesthesiol Clin 2015; 33: 447-56.

22. Ptasinska AP, Materkowska DD, Bartczak A, et al. Kidney disease in the elderly: biopsy based data from 14 renal centers in Poland. BMC Nephrol 2016; 17: 194.

23. McDaniel C, Ratnani I, Fatima S, Abid MH, Surani S. Urinary incontinence in older adults takes collaborative nursing efforts to improve. Cureus 2020; 12: e9161.

24. O'Hare AM, Song MK, Tamura MK, Moss AH. Research priorities for palliative care for older adults with advanced chronic kidney disease. J Palliat Med 2017; 20: 453-60. 
25. Nicaise AM, Willis CM, Crocker SJ, Pluchino S. Stem cells of the aging brain. Front Aging Neurosci 2020; 12: 247.

26. Gallagher M, Okonkwo OC, Resnick SM, Jagust WJ, Benzinger TLS, Rapp PR. What are the threats to successful brain and cognitive aging? Neurobiol Aging 2019; 83: 130-4.

27. Sarıcam G, Kahveci K, Akdoğan D. Palliative care requirement in neurologic diseases. Turk J Neurol 2020; 26: 153-9

28. Xu X, Wang B, Ren C, et al. Age-related impairment of vascular structure and functions. Aging Dis 2017; 8: 590-610.

29. Feigin VL, Lawes CM, Bennett DA, Anderson CS. Stroke epidemiology: a review of population-based studies of incidence, prevalence, and case-fatality in the late $20^{\text {th }}$ century. Lancet Neurol 2003; 2: 43-53

30. Sarıcam G, Akdogan D, Kahveci K. Palliative care after stroke. Acta Neurologica Belgica 2019; 119: 69-75.

31. Mioche L, Bourdiol P, Peyron MA. Influence of age on mastication: effects on eating behaviour. Nutr Res Rev 2004; 17: 43-54

32. Funk MC, Zhou J, Boutros M. Ageing, metabolism and the intestine EMBO Rep 2020; 21: e50047.

33. Beld AW, Kaufman JM, Zillikens MC, Lamberts SWJ, Egan JM, Lely AJ. The physiology of endocrine systems with ageing. Lancet Diabetes Endocrinol 2018; 6: 647-58.

34. Kalyani RR, Egan JM. Diabetes and altered glucose metabolism with aging. Endocrinol Metab Clin North Am 2013; 42: 333-47.

35. Russo CR, Lauretani F, Bandinelli S, et al. Aging bone in men and women: beyond changes in bone mineral density. Osteoporos Int 2003; 14: 531-8.

36. Novotny SA, Warren GL, Hamrick MW. Aging and the musclebone relationship. Physiology (Bethesda) 2015; 30: 8-16

37. Eckhart L, Tschachler E, Gruber F. Autophagic control of skin aging. Front Cell Dev Biol 2019; 7: 143.

38. Sator PG, Schmidt JB, Rabe T, Zouboulis CC. Skin aging and sex hormones in women- clinical perspectives for intervention by hormone replacement therapy. Exp Dermatol 2004; 13: 36-40

39. Çivi S, Tanrıkulu Z. Yaşlılarda bağımlılık ve fiziksel yetersizlik düzeyleri ile kronik hastalıklar prevelansını saptamaya yönelik epidemiyolojik çalışma. Türk Geriatri Derg 2000; 3: 85-90.

40. Jones E, Sheng J, Carlson J, Wang S. Aging-induced fragility of the immune system. J Theor Biol 2021; 510: 110473.

41. Finucane TE, Nirmalasari O, Graham A. Palliative care in the ambulatory geriatric practise. Clin Geriatr Med 2015; 31: 193 206

42. Voumard R, Rubli Truchard E, Benaroyo L, Borasio GD, Büla C, Jox RJ. Geriatric palliative care: a view of its concept, challenges and strategies BMC Geriatrics 2018; 18: 22 